\title{
Analysis on the present situation and Reform practice of higher Vocational Education of Medical examination
}

\author{
Yan Zhao ${ }^{1}$, Fengying Zheng ${ }^{2}$, Hongjuan Song ${ }^{3}$, Yonghua Xuan ${ }^{4}$, Hong $\mathrm{Xu}^{5}$ \\ Department of Medicine, Binzhou Polytechnic College, Binzhou, 256600, Shandong, China \\ email:zhaoyanyan2006@126.com
}

Keywords: Medical examination; Higher vocational education; Kurrent situation analysis; Reform practice

\begin{abstract}
In recent years, medical examination has become a popular specialty in higher vocational education. This article mainly analyzes the current situation of medical laboratory higher vocational education, finds out the reasons, determines the orientation of the training goal of medical examination in higher vocational education, from the curriculum setting, the construction of teaching materials, The teaching methods and means should be improved and the new teaching orientation should be set up in the aspects of practical teaching and students' achievement evaluation in order to give full play to the due role of higher vocational education of medical examination.
\end{abstract}

\section{Introduction}

Medical laboratory has become a hot specialty in medical development in recent years. With the rapid development of science and technology, medical laboratory has begun to infiltrate with clinical medicine, and the work content of clinical laboratory has changed greatly under the background of social development. The demand for talent has also undergone historic changes. There are two main characteristics of medical laboratory talents at the present stage, one is laboratory examination talents, the other is compound medical laboratory talents combined with clinical medicine. Higher vocational education itself is to train professional and technical talents, so how to improve the level of medical laboratory teaching in higher vocational colleges, in order to adapt to medical units, especially at the grass-roots level The requirement of inspection in health units is a problem worth studying in higher vocational colleges of medical laboratory at present.

\section{Analysis on the present situation of higher Vocational Education of Medical examination}

\subsection{Shortage and decline in quality of higher Vocational College students enrolled through College entrance examination}

In the past, higher vocational students recruit students through the way of college entrance examination, aiming at the students with unsatisfactory results in the college entrance examination, they are provided with the way of vocational education[1]. However, in recent years, the phenomenon of low registration rate of higher vocational students enrolled through the college entrance examination is mainly due to the lack of understanding of higher vocational education among many students, who believe that the lower academic qualifications of vocational college students will become an obstacle to finding a job in the future. So most students choose to repeat. Higher vocational colleges will have to reduce the number of students because of the shortage of places, so that the quality of students will decline, students' ideological work will be difficult to do, teaching quality will be difficult to guarantee, therefore, it will bring certain degree to the teaching work in the future. A degree of hindrance.

\subsection{The disconnection between teaching and learning is serious.}

With the development of social economy and the continuous improvement of biological science 
and technology, there is a trend of multivariate development in clinical testing items, and the phenomenon of polarization in laboratory is obvious. Multi-disciplinary integration, and fast bedside detection began to move towards social groups. However, medical laboratory teaching in higher vocational education is still carried out in the traditional way, which is far from clinical examination in the new period. As a result, students can not apply the knowledge they have learned quickly to clinical testing in the future practice[2]. As far as the hardware of medical testing in higher vocational colleges is concerned, it is still at the previous level. Students are unable to understand the application of the new equipment. They have always mastered the application skills of the previous equipment. And students have not yet left the laboratory behind the social embarrassing situation.

\subsection{Students have less chance of clinical examination}

In medical laboratory teaching in higher vocational education, the only way for students to contact clinical tests is through the experimental teaching in this school. There is still a big gap between the experimental teaching and the real clinical experience, which leads to the students accepting the experimental teaching for a certain period of time. Nor can it really feel the real clinical test, which has a great adverse effect on the cultivation of technical talents.

\subsection{Lack of standardization in the test of experimental skills}

Although the higher vocational college is a professional and technical college, it pays too much attention to the cultivation of students' professional knowledge and neglects the cultivation of students' professional technology in the process of training real talents. In the examination of medical laboratory specialty, the examination of theoretical knowledge is the main way of examination, and the examination of students' experimental skills is often a one-off, and the degree of attention is low. The examination of medical laboratory skills is usually in the class. When the general teacher carries on the experiment class teaching to the student, has carried on the inspection to the student's experimental skill by the way, the inspection way is relatively rough, lacks the standard. And because of this kind of nonstandard test. The nuclear method causes the students to pay little attention to the operation of the experimental class, and the ability of operation is decreased, and the steps of medical examination can not be operated in detail, thus affecting the training goal of medical education and teaching in higher vocational education. It affects the quality of the training of applied professionals.

\section{Orientation of training goal for Medical Laboratory students in higher Vocational Colleges}

This paper analyzes the current situation of medical laboratory education in colleges and universities in China in the new period. If the medical laboratory education in higher vocational colleges is to meet the needs of the current social development, it is necessary to make clear the training objectives of medical laboratory students in the new period. According to our country's current requirements for the training of medical laboratory professionals in higher vocational education, it is determined that the goal of training medical laboratory professionals in higher vocational education should be focused on "two faces, two abilities, three skills", that is, for the students at the grass-roots level. Face to the basic knowledge, attach importance to the cultivation of the students' computer ability and English communication ability, strengthen the training of the students' basic experimental skills, professional operation skills and medical laboratory comprehensive skills. Carry out the medical laboratory teaching to the students, and train the students to develop in an all-round way[3]. The following will mainly put forward some teaching reform suggestions on the realization of the goal of higher vocational education of medical laboratory. 


\section{Reform practice of higher vocational teaching goal of medical examination}

\subsection{Optimizing the Curriculum Design of Medical Laboratory Specialty}

At present, most of the courses in higher vocational colleges in our country are divided into sections, which adopt the flow of culture, medical basic, professional and experimental courses, with distinct structure and obvious center[4]. However, in view of the situation of social development in the new period, the educational and teaching mode has been seriously out of line with the trend of social development, even hindering the development of higher vocational education to a greater extent. Medical laboratory majors train advanced technical talents in laboratory positions. Therefore, the curriculum should be competency-based, and then, according to the requirements of current medical laboratory posts for students' ability, the goal of post examination ability should be determined. And then separate out the other targets. Finally, in order to meet these objectives, the curriculum is designed as follows: (1) the job objectives of curriculum setting should be clear. (2) flexible curriculum modules should be set to ensure that the curriculum can adapt to the changes at will according to the requirements of scientific development. In order to maintain the advanced nature of the curriculum and the times. (3) the curriculum should be open so that the students can flexibly change the curriculum modules according to their own circumstances so as to effectively improve the students' learning ability.

\subsection{Optimizing the Construction of Teaching Materials}

The content of the textbook is updated slowly. In many cases, only by learning the knowledge of the content of the textbook can we master a concept or technology completely. If we want to learn a certain knowledge completely, we need not only the knowledge of the textbook as a reference, but also the trend of social development. Integrate useful information and continue to supplement the content of teaching materials. In addition, higher vocational colleges can change teaching materials in time according to the development of the times, so as to display the latest and most complete knowledge to students. Textbook compilers should also keep pace with the times, extensively listen to the opinions and suggestions of the leading representatives of clinical laboratory work and clinicians, constantly optimize and supplement the contents of teaching materials, and avoid teaching as a result of teaching in the course teaching. The low-level repetition of material content leads to the low teaching level of the whole medical laboratory specialty.

\subsection{Strengthening the practical Teaching of students}

It is mentioned in the present situation that in higher vocational teaching of medical laboratory, students seldom have the opportunity of actual examination, which leads to the students being unable to have practical experience of medical examination. In the traditional teaching of medical laboratory major, students are usually taught basic courses first. After the completion of all the courses, the school begins to offer practical courses to students, which seriously leads to the disconnection between the basic courses and the practical courses. Cause students to lose interest in learning. Therefore, in order to effectively improve the teaching level of higher vocational colleges of medical examination and improve the students' ability of medical examination, the school began to improve the curriculum design, increase the practical teaching of students, and make use of the students' spare time. Organize students to participate in laboratory, clinical laboratory experiment preparation and skill operation practice activities, so that students can better complete the study of medical test on the basis of personal experience. It can effectively help students to have a direct and objective understanding of the knowledge and skills required for the inspection of the post.

\subsection{Perfect the way of evaluating students'Achievement}

For a long time, the assessment methods of medical students' results are mainly based on book knowledge and mainly based on theoretical examination, ignoring the assessment of students' practical ability, which directly affects the improvement of students' medical laboratory technology. Therefore, in view of the new situation of medical development, higher vocational colleges of 
medical laboratory should constantly improve the evaluation method of students' achievement, increase the examination method of medical laboratory technology, change the past closed examination into open-book examination, and increase the difficulty of the subject appropriately. Lighten the student's psychological pressure, so that students have more time and energy to participate in skills training. In the examination of medical laboratory techniques, teachers can do exercises through students' practice. The performance has a preliminary judgment on the students' medical testing skills, and then it can be carried out targeted training for the students in the next teaching.

\section{Conclusion}

In recent years, with the increasing demand of medical laboratory talents, the higher vocational colleges of medical laboratory require more and more talents[5]. Through the analysis of the present situation of medical laboratory higher vocational education, and the realization of its goal in the new period, this paper discusses the reform practice, and looks forward to providing reference for the relevant schools.

\section{Acknowledgement}

In this paper, the research was sponsored by Project of Scientific Research of Binzhou Polytechnic College (Project No. 2013XYKT121) and Project of Scientific Research of Binzhou (Project No. 2013KT11).

\section{References}

[1] Ding Huanyu, gan Xiaoling, Wu Zhengji, Tang Yi. Reconstruction of higher Vocational Medical Laboratory Education Curriculum system based on comparison between China and America [J]. Chongqing Medical Science, 2016, 45 (08): 1145-1146.

[2] Cao Jing Yi. A brief talk on the present Employment situation of graduates majoring in Medical Laboratory Technology in higher Vocational Education [J]. Education Forum, 2014 (19): 175-176.

[3] Huang Xiangjuan. The present situation and Prospect of higher Vocational Education of Medical examination [J]. Laboratory Medical Education, 2005 (01): 10-11.

[4] Vocational medical examination shows how to embody the characteristics of higher vocational education, J.J . Health Vocational Education, 2004 (13): 9-10 .

[5] Lu Yuyun. Seize the opportunity to develop medical laboratory education in higher vocational education [J]. Health Vocational Education, 2002 (09): 16-17. 